\title{
O governo das signorie na crônica de Salimbene de Parma
}

\section{Lorene Correia Santos*}

DOI: 10.11606/issn.2318-8855.v10i2p488-517

Resumo: As crônicas medievais foram produzidas nas cidades e, tanto em seu caráter laico quanto eclesiástico, compreendem dimensões educativas e políticas. A tradição cronística é um fenômeno importante na construção social e organização política das comunas italianas durante o século XIII. Tendo isso em vista, este artigo é composto de três momentos que se entrecruzam: 1) o traçado de uma perspectiva do fazer cronístico citadino e mendicante, buscando entender sua importância nas cidades, para assim intentar inserir a Crônica de Salimbene de Parma - escrita entre os anos 1229-1268, e que possuiu um tecido textual com traços de diferentes gêneros narrativos - nesse contexto de produção; 2) um panorama do advento das signorie nas cidades, essas formas de governo surgidas em meados do século XIII e que trouxeram uma nova configuração para a dinâmica política e institucional do sistema comunal; 3) a análise de alguns relatos de Salimbene acerca de governos para entender o que o minorita apreciava ou condenava neles.

Palavras-chaves: Comunas Italianas, Crônicas Mendicantes, Governo, Salimbene de Parma, Signorie

* Graduada em História pela Faculdade de Filosofia e Ciências Humanas da Universidade Federal de Minas Gerais (UFMG). Contato: correialorene@gmail.com 


\section{O poder na Idade Média}

\section{O Governo das signorie na Crônica de Salimbene de Parma}

\section{Introdução}

O presente artigo pretende analisar as caracterizações que Salimbene de Parma (1221-1290) constrói em sua Crônica sobre as signorie, que ele observa nas comunas italianas de fins do século XIII. A obra foi escrita pelo frade franciscano, provavelmente de 1229 a 1268 e abrange uma profusão de eventos, principalmente na Itália, de 1168 a 1288.

Salimbene de Adam nasceu em Parma em 1221, em 1238 ingressou na Ordem dos Frades Menores e durante sua vida percorreu diversas cidades da Itália Setentrional e da França. Sua Crônica é permeada de registros das diversas coisas que viveu e presenciou, além de múltiplas referências a eventos mais antigos. A extensão das experiências presentes na Crônica é o primeiro dos muitos fatores que fazem da obra uma fonte rica para o estudo tanto das comunas italianas como da própria ordem dos frades menores. "Ao ouvir o frade em meados de seus sessenta anos, refletir sobre seus cinquenta anos na Ordem, não é possível evitar maravilharse com a extensão de sua experiência. Isto é, claro, o que o torna uma fonte tão maravilhosa para o estudo dos frades e das comunas" (FOOTE, 2011, p. 203, tradução nossa) ${ }^{1}$. Essa relevância é ainda mais evidente quando se considera o pressuposto franciscano de participação no mundo e na dinâmica interna das cidades: consideradas o núcleo de pecados e falhas morais, eram os espaços que mais precisavam de sua presença e pregação.

O período das signorie é o menos estudado da história comunal do século XIII,

\footnotetext{
${ }^{1}$ No original: "As one listens to the friar in his mid sixties reflect upon his fifty years in the order, one cannot help but be amazed at the breadth of his experience. This is, of course, what makes him such a wonderful source for a study of the friars and communes" (FOOTE, 2011, p. 203).

2 Optamos pelo uso das palavras, "signoria", "signorie", "signori" e "signorile" em seus originais italianos para evitar conflitos e ambiguidades com os vocábulos em português "senhorio", "senhoria", "senhorial" que podem confundir por serem geralmente usados para falar do contexto feudal.
} 


\section{O poder na Idade Média}

Lorene Correia Santos

ou das "quatro idades das cidades italianas" (GILLI, 2011, p. 57). As signorie nascem no interior das comunas como uma nova configuração política: o governo de um só indivíduo. Por vezes, são interpretadas como o resultado de uma constante crise institucional, ou mesmo o regime responsável pela destruição da dinâmica comunal e ascensão do despotismo ${ }^{3}$. Entretanto, esse ponto de vista vem sendo questionado e ressignificado. Assim, acreditamos que a busca por outras nuances dessa temática seja pertinente para o melhor entendimento da dinâmica política do recorte espaçotemporal comunal italiano.

Na primeira parte, traçaremos um breve panorama das crônicas citadinas e mendicantes, relacionando-as com o papel que desempenharam no seio das comunas, principalmente no esforço citadino de construção de suas identidades e afirmação de sua autogestão. Na segunda parte, trataremos da questão das signorie, buscando entender o que essa nova forma de governo, mais centralizada que as precedentes, significou no contexto comunal de experimentação governamental e política. Por fim, partindo do contexto intelectual, social e político de Salimbene, e tendo em vista os fatores que se entrecruzam nas reflexões que constrói, analisaremos os governantes e seus atributos considerados por Salimbene: quais são válidos e necessários no exercício do poder, ou quais condena como inadequados e viciosos.

\footnotetext{
${ }_{3}$ Para exemplificar essas perspectivas, destacamos os trabalhos de, COLEMAN, Edward. The Italian communes. Recent work and current trends. Journal of Medieval History, Grã-Bretanha, v.25, n.4, p. 373-397, 1999.

e, BLANSHEI R., Sarah. Introdução. In: Politics and Justice in Late Medieval Bologna, $1^{\circ}$ ed. Boston, 2010. p. 1-15., onde os autores traçam panoramas, discutem as mencionadas correntes historiográficas, suas interpretações e debates.
} 


\section{O poder na Idade Média}

\section{O Governo das signorie na Crônica de Salimbene de Parma}

\section{As Crônicas citadinas, as Crônicas mendicantes e a Crônica de Salimbene}

As crônicas foram um gênero narrativo que buscava abarcar registros do tempo e episódios importantes para as entidades que as produziam, a saber, principalmente os órgãos oficiais citadinos e as ordens religiosas. No medievo, esse gênero teve o apogeu de sua produção no decorrer dos séculos XIII e XIV. As crônicas também compreendem os mais variados aspectos de seus contextos sociais, não se atendo apenas às autoridades eclesiásticas ou régias, mas sim incorporando um esforço de construção e narração do passado e entendimento do presente. Nelas, não se buscava uma narração passiva dos acontecimentos, ao contrário, sua produção é inseparável da intenção e do desempenho de um papel educativo e político, e essas características estão presentes tanto em crônicas laicas quanto eclesiásticas ${ }^{4}$.

Atentar-se às razões de produção de determinada crônica é crucial para sua apreensão e da análise da escrita da história no medievo. Se os tratados políticos deixavam transparecer suas motivações, aspirações e o vislumbre de algumas questões latentes naquele período, a presença desses mesmos fenômenos nas crônicas, tanto mendicantes quanto citadinas, também é uma constante. Esses escritos nos dizem muito dos aspectos histórico, social e político do meio e do tempo nos quais foram produzidos.

\footnotetext{
4 Como afirma Miatello, ao diferenciar a produção historiográfica monástica da mendicante, percebemos que assim como os frades, “[...] os monges, pretendiam usar a historiografia para ensinar a moral monástica e defender a legitimidade e/ou o poderio regional deste ou daquele mosteiro. Sucede que, no geral, as crônicas e histórias monásticas conheciam uma difusão restrita ao espaço do mosteiro, quando muito dentro da congregação monástica [...] Em contrapartida, as crônicas mendicantes de difundiam de maneira mais ampla, seja porque o número de conventos era imenso, ou porque as Ordens mendicantes eram centralizadas, diferentemente das Ordens monásticas, ou ainda porque os frades eram itinerantes e seus conventos, ao contrário dos mosteiros, mão eram claustros mais ou menos impermeáveis aos leigos e às populações urbanas" (MIATELLO, 2011, p.3).
} 


\section{O poder na Idade Média}

Lorene Correia Santos

\subsection{O fazer cronístico citadino e o fazer cronístico mendicante}

As crônicas citadinas foram escritas e no interior das comunas italianas. Foram produzidas para desempenhar o papel de voz oficial das cidades, enquanto também atendiam à necessidade da escrita de uma história citadina. Compostas muitas vezes no interior das magistraturas urbanas, elas contam a sucessão de eventos que traduzem a história da cidade, enquanto essa é seu principal núcleo narrativo. A utilidade dessa escrita se deu principalmente porque o regime político que as comunas experimentavam era inédito, e a construção sistemática de uma narrativa que conectasse o regime novo ao passado ${ }^{5}$ foi necessária para justificar sua existência.

(...) a absorção progressiva da cidade pela comuna, em outras palavras, a conquista de um espaço físico ocupado por jurisdições antigas e legítimas (episcopais ou condais), por instituições novas, sem outra justificativa que as novas relações de forças políticas e sociais no seio da cidade, só pôde se realizar ao preço da criação progressiva de uma identidade urbana e de uma consciência cívica. Claro, a Itália do Centro-Norte tinha uma longa tradição urbana testemunhada pelos laudes civitatum (elogios das cidades) redigidos na Alta Idade Média. Mas, entre o orgulho de habitar uma cidade, às vezes ornamentada de uma grande antiguidade e de fundadores míticos, e o orgulho de pertencer a uma comunidade cívica unida em torno de valores políticos comuns há um passo considerável. Essa passagem se realizou graças à promoção, muitas vezes dolorosa, de ideias algumas vezes antigas, rejuvenescidas nos séculos XII e XIII. (GILLI, 2011, p. 367-368)

Nessa perspectiva, não é difícil entender a intencionalidade desses escritos ao se preocuparem com temas locais e com o registro de sua própria história política. Como afirma (GILLI, 2011, p.368), ao longo do século XIII, o relato adquire um papel de

\footnotetext{
5 É evidente que esse esforço não se deu só no âmbito da escrita das crônicas. Juízes e notários também desempenharam importantes papéis nesse empreendimento, principalmente como divulgadores das ideias políticas. Esta, retomava o léxico da romanidade e nele buscava conceitos operantes como o de bem comum (bonum commune) sob intenção de aplicá-los ao presente (GILLI, 2011, p.369).
} 


\section{O poder na Idade Média}

\section{O Governo das signorie na Crônica de Salimbene de Parma}

destaque na consciência urbana. Seus autores, marcados amiúde pelas cisões internas, insistem na necessidade da paz cívica e do respeito às instituições.

(...) esse movimento de emancipação política, que atingiu boa parte das cidades da cristandade ocidental desde meados do século XII e por todo o século XIII, não teria alcançado a amplidão de suas reformas se não fosse pela força ideológica advinda da historiografia então produzida segundo os intentos e as necessidades dos centros urbanos em expansão. A função cívica atrelada à historiografia, o caráter público do monumento literário - chamado crônica ou história - e a sua leitura declamada em assembleia dão uma dimensão política ímpar às narrativas historiográficas, não raro financiadas pelas municipalidades. (MIATELLO, 2011, p. 1)

Ou seja, o contexto de tensões inter e intra-urbanas, frente à ameaça imperial ou mesmo às longas guerras civis, também foi motivador e justificador da produção dessas histórias citadinas, como parte do esforço de estruturação de sua autonomia e autogoverno. Para (GILLI, 2011, p.367), ao discutir os valores cívicos e de bom governo, é perceptível que as ideias políticas da cidade se desenvolvem em simbiose com suas instituições, enquanto norteiam-se por temas como valores cívicos da identidade urbana e consciência cívica: liberdade, paz e bem comum.

No contexto das ordens religiosas, principalmente a Ordem dos Frades Menores e a Ordem dos Frades Pregadores, as crônicas encontravam lugar junto à pregação como dispositivos de instrução e persuasão na dinâmica citadina. Por vezes, serviam também como compêndios de exemplos, bons, passíveis de serem seguidos e imitados, ou maus, advertências do quanto deveriam ser rejeitados. "Se a historiografia dita medieval constituía mais um instrumento de persuasão da providência do que uma análise apurada dos fatos, podemos deduzir que os frades mendicantes encontraram nela um poderoso artifício de difusão de suas ideias" (MIATELLO, 2011, p. 3). As crônicas mendicantes viram sua proficuidade como gênero escrito ascender para além dos aspectos citados: elas também se tornaram parte do 


\section{O poder na Idade Média}

Lorene Correia Santos

esforço de legitimação da ação das ordens nas cidades. Ainda nesse sentido, a relação entre mendicantes e as cidades nas quais estavam presentes é ampla e complexa, principalmente considerando que essas constituíam seus núcleos espirituais e materiais. Portanto, ainda que a pregação fosse a principal atividade dos mendicantes nas cidades, não era a única, e levando em conta sua grande presença no meio dessas $^{6}$, é difícil encontrar aspectos da vida social que não se relacionem de alguma forma com suas atividades.

Entretanto, as crônicas mendicantes não parecem possuir um só tema central e específico: (CAPO, 1977, p.633) aponta a impossibilidade de definir as crônicas mendicantes em um padrão fixo, tendo em vista sua individualidade, espontaneidade e ausência de programa normativo ou especificidade para sua produção, mesmo diante da variedade entre as obras. "Em relação à cidade, a distinção é clara, pelo horizonte de informações, que é eclesiástico, ou seja, sobretudo mendicante, (...) e sobretudo pelo horizonte mental, que é alimentado pela cidade, mas é conscientemente não laico" (CAPO, 1977, p.635, tradução nossa)7. Portanto, ao generalizar a produção cronística, tanto eclesiástica quanto mendicante, desconsidera-se sua ampla multiplicidade interna, assim como a complexidade que permeia a relação das Ordens religiosas com as comunas. "O encontro entre as crônicas citadinas e as crônicas mendicantes se deu, de fato, precisamente quando os modelos historiográficos usuais nas cidades se mostraram obsoletos, e, portanto, novas soluções se fizeram necessárias" (ZABBIA, 2018, p. 223, tradução nossa).

\footnotetext{
${ }^{6}$ David Foote expõe que as estatísticas acerca dos assentamentos franciscanos nos dão uma ideia de quão bem-sucedido foi o movimento na Itália. Em 1230, vinte anos após sua fundação, já havia quatrocentos conventos Franciscanos. Em meados do século XIII, cerca de dez mil minoritas apenas na Itália (FOOTE, 2011, p. 199).

${ }^{7}$ No original: "Rispetto alla città la distinzione è netta, per l'orizzonte di informazioni, che è ecclesiastico, cioè soprattutto mendicante (...) e soprattutto per l'orizzonte mentale, che è alimentato dalla città, ma che è coscientemente non laico (...)".
} 


\section{O poder na Idade Média}

\section{O Governo das signorie na Crônica de Salimbene de Parma}

\subsection{A Crônica de Salimbene de Parma}

Para identificar as características das crônicas citadinas, Marino Zabbia propõe um certo nível de generalização: “(...) em primeiro lugar, o horizonte do relato, centrado sobre a cidade, vai tão longe quanto o interesse político dela; em seguida a atenção prevalente, quando não exclusiva, e reservada à história contemporânea; frequente em diversas partes destas crônicas e nas obras dos leigos" (ZABBIA, 2018, p. 223 , tradução nossa) ${ }^{8}$. A obra de Salimbene chegou aos nossos dias fragmentada, com diversos de seus fólios perdidos e nem mesmo seu título original sabemos ${ }^{9}$. No texto, encontramos traços de diferentes gêneros na narrativa, que vão da Genealogia à História Universal. O minorita se esforça para percorrer eventos que vão de 1168 a 1288, se inserindo em um contexto de disputas entre as comunas e o Império, das comunas entre si e também nos conflitos de suas facções internas. Assim, a Crônica de Salimbene é um exemplo dissidente do que poderíamos identificar como padrão cronístico, ainda que essa definição também seja um empreendimento difícil.

(...) inclassificável com base em protocolos de gênero e posicionado entre a perspectiva escatológica e o tempo diário, a Crônica se apresenta como um grande "saco" no qual podemos encontrar o evento histórico, anedota, a legenda, a profecia, as pestilências, as superstições, os milagres, terremotos, eclipses, a disputa teológica, carestia, os exempla, memórias pessoais, e textos sacros, em um contínuo entrelaçar e contaminar-se de "alto" e de "baixo". (LAVAGETTO, 2006, p. VII, tradução nossa) ${ }^{10}$

\footnotetext{
${ }^{8}$ No original: “(...) in primo luogo l'orizzonte del racconto e centrato sulla citta e spazia sin dove arriva l' interesse politico della citta stessa; poi l'attenzione prevalente, quando non esclusiva, e riservata alla storia coeva; infine tanta parte di queste cronache e opera di laici".

${ }^{9}$ Como aponta Miatello, é nesses fólios iniciais perdidos "onde certamente encontraríamos o prólogo e, com ele, as razões, os fundamentos teórico-teológicos, os objetivos, os procedimentos narrativos [...]" (MIATELLO, 2011, p.9).

10 No original: Inclassificabile in base a protocolli di genere e in bilico tra prospettiva escatologica e tempo quotidiano, la Cronica si presenta come um grande "sacco" in cui possiamo trovare l'evento storico, l'aneddoto, la legenda, la profezia, le pestilenze, le supertizioni, i miracoli, i terremoti, le eclissi, le dispute teologiche, le carestie, gli exempla, i ricordi personali e i testi sacri, in um continuo intrecciarsi e contaminarsi di "alto" e di "basso".
} 


\section{O poder na Idade Média}

Lorene Correia Santos

O minorita reafirma seu lugar de pregador no texto e a delimitação desse espaço indica o quão importante a experiência franciscana foi para ele (MILNE, 2010, p. 51). Para narrar os eventos, por vezes relata o que observa "com seus próprios olhos" e por vezes recorre à literatura cronística produzida previamente como fonte histórica.

(...) partindo de si mesmo e tendo a sua vida, a de sua família e de sua Ordem religiosa como referências centrais, Salimbene constrói a crônica entrelaçando história local e geral, política e psicológica, eclesiástica e civil. Encontramos desde a receita da torta que o deliciou certa feita até a descrição de revoluções político-sociais de cidades e reinos. (MIATELLO, 2011, p. 8)

Levando em conta esses múltiplos aspectos e sua complexidade, Milne (2010, p.8-9) propõe que a obra seja tratada como uma História Universal ${ }^{11}$, ainda que tampouco corresponda ou se enquadre nos preceitos fixados desta, aliás preceitos esses definidos pela historiografia posterior. Sua proposta é que se busque entender como as diversas mudanças que permearam o cenário social, político e religioso do período possibilitaram a busca por novos formatos escritos que abarcassem esse mundo em transformação. ${ }^{12}$. Nem a escrita da história era uma operação passiva nem seus preceitos "obrigatórios" eram estruturas estáticas, mas respondiam às

\footnotetext{
11 De acordo com Milne, as Histórias Universais eram "De forma geral, um trabalho histórico que começava em um "começo", normalmente associado com as origens do Cristandade e incorporava eventos mundanos - ou melhor, o mundo como ele se relacionava à comunidade do autor - em uma representação linear. Por vezes, isso significava que o autor começaria pela Criação, o nascimento de Cristo, ou mesmo pelas origens mitológicas de sua cidade[...]" (MILNE, 2011, p.10, tradução nossa). No original: "Generally speaking, 'universal' was an historical work that started from a 'beginning' usually associated with the origins of Christianity and incorporated worldly events - or rather the world as it related to the writer's community - into a linear representation. Sometimes this meant that the author would begin from the Creation, the birth of Christ, or even from the mythological origins of their city $(\ldots)^{\prime \prime}$

${ }^{12}$ No original: L'incontro tra cronachistica cittadina e cronachistica dei frati mendicanti avvenne, infatti, proprio mentre modelli storiografici usuali in ambito cittadino si stavano rivelando obsoleti e quindi urgevano nuove soluzioni.
} 


\section{O poder na Idade Média}

\section{O Governo das signorie na Crônica de Salimbene de Parma}

transformações do mundo, de sua audiência e sua função. "A História Universal proporcionava estrutura flexível na qual Salimbene poderia, como argumentou Flint, distinguir, acomodar e incluir o diálogo crescente e entre as esferas religiosa e social"

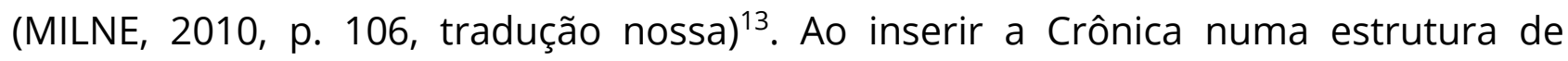
produção historiográfica maior, percebe-se nas décadas de sessenta e setenta do século XIII um esforço em produzir Histórias Universais destinadas a perdurar, além de sua proximidade com as crônicas.

O texto de Salimbene nos diz da Itália de sua época, mas também de sua vida. O envolvimento do minorita em sua própria narrativa nos fornece detalhes pessoais e de suas vastas experiências (MILNE, 2010, p.5). Essa presença no texto, segundo Milne (2010, p.14) corresponde muito mais às vias de reafirmação de uma autoridade textual, a sua auctoritas como testemunha, do que algum interesse autobiográfico em sua história individual.

Para falar do que não pode presenciar, como eventos anteriores à segunda década do século XIII, Salimbene evoca outras obras e autores do período em questão, dentre os quais encontramos: Sicardo de Cremona (1155-1215), que é sua principal fonte ${ }^{14}$; Vicente de Beauvais (1190-1264); Alberto Milioli (1220-1285/1287); Joaquim de Fiore (1135-1202); Santo Agostinho; São Boaventura (1221-1274); dentre outros. Outra profusa fonte de referências é a Bíblia, a qual usa com frequência para sustentar suas afirmações e opiniões.

O frade relata diversas guerras e conflitos travados entre as facções no interior

\footnotetext{
${ }^{13}$ No original: Universal history provided a flexible framework in which Salimbene could, as Flint argued, distinguish, contain and accommodate the increasing dialogue between the religious and social spheres.

${ }^{14}$ Segundo (RONZANI, 2018, p.253), Salimbene se baseou em Sicardo de Cremona para escrever sobre todos os eventos anteriores à segunda década dos anos 1200.
} 


\section{O poder na Idade Média}

Lorene Correia Santos

das comunas, entre as próprias cidades e, em maior escala e consequências, entre Igreja e Império, numa espécie de análise da Itália do século XIII: “o esqueleto da crônica de Salimbene é a narrativa política das comunas do norte-centro italiano (Toscana, Úmbria, Marcas, Emília-Romanha, Vêneto, Lombardia ${ }^{15}$ e Ligúria) [...]" (FOOTE, 2011, p. 227, tradução nossa) ${ }^{16}$. A crônica é também um comentário franciscano, ou seja, o frade também se dedica a contar episódios e tecer reflexões sobre a história da Ordem. Segundo Miatello, a obra “(...) é um dos poucos testemunhos de finais do século XIII que nos contam a versão da história franciscana própria dos frades que compunham a chamada "Comunidade", isto é, a ala da Ordem minorítica contra a qual se opunham os frades "zelantes" ou "espirituais" (MIATELLO, 2011 , p. 6). Entretanto, isso não significa que a crônica era amplamente lida ou citada dentro da Ordem, pelo contrário, no que tange a referências contemporâneas, somente Alberto Milioli faz menção a ela (MILNE, 2010, p.102).

Salimbene é um observador atento e testemunha de grande parte dos eventos que conta. Ele não se pretende objetivo nem neutro, mas sim, "A ele interessa identificar a evolução de várias situações locais, o aumento do comércio, a expansão da riqueza. Sem dúvidas, ele não aprova as lutas e rivalidades entre os municípios, e as diferentes facções entre seus habitantes" (PEPE, 2012/2013, p. 28, tradução nossa $)^{17}$. Nascido em uma linhagem de ricos comerciantes (MIATELLO, 2011, p.8), sua origem abastada, assim como seu sentimento político, são evidenciados em seu texto e parte importante de suas opiniões: é crítico à admissão na ordem de membros

\footnotetext{
15 É importante notar que no contexto de Salimbene, a concepção de "Lombardia" correspondia a todo o Norte da Itália e não apenas ao seu território contemporâneo.

${ }^{16}$ No original: The skeleton of Salimbene's chronicle is a political narrative of the north-central Italian communes (Tuscany, Umbria, Marche, Emilia-Romagna, the Veneto, Lombardia, and Liguria) [...].

17 No original: "A lui interessa individuare l'evolversi delle varie situazioni locali, I'incremento dei commerci, l'espansione delle ricchezze. Indubbiamente, non approva le lotte tra i Comuni e le rivalità tra le diverse fazioni dei loro abitanti".
} 


\title{
O poder na Idade Média
}

\section{O Governo das signorie na Crônica de Salimbene de Parma}

incultos (CAPO,1977, 637), das cisões internas nas cidades, dos empreendimentos de conquista de Frederico II e, apesar de não se pautar apenas por isso, o minorita é claramente Guelfo ${ }^{18}$. Portanto, os conflitos, mudanças e contendas que se deram no interior das comunas italianas durante todo o século XIII também são partes importantes na construção do discurso de Salimbene e significativas em sua obra.

\section{0 advento das signorie}

O regime comunal assistiu à ascensão e queda de diferentes formas de governo: enumerando-as em quatro, temos a fase consular, do fim do século XI à Paz de Constância (1183); a 'podestadal' do fim do século XII até a metade do XIII; a comuna do popolo, até o início do XIV; e as signorie, em alguns casos, desde a primeira metade do século XIII (GILLI, 2011, p.58). Assim, o espaço político comunal sempre foi palco de disputas entre as diferentes esferas de seu corpo cívico. É possível pensar o contexto das comunas italianas como complexo, dotado de uma dimensão política diversa e permeado de experimentos e reconfigurações de poder. Isto é, as comunas foram sociedades de conflito por excelência.

\begin{abstract}
O quadro político da Itália das cidades centro-setentrionais parece mais rico e variado se não for considerado apenas sob uma visão prevalentemente "comunal". Regimes diversos e híbridos se alternaram, a partir da crise do regime podestadal na idade federiciana, com êxitos frequentemente instáveis e incertos, e, às vezes, mais estáveis e duradouros. Essa aparente instabilidade institucional foi a expressão de uma intensa experimentação política, que não ocorreu apenas no traço da participação ampliada, mas também no governo pessoal e monocrático. (ZORZI, 2008, p. 69, tradução nossa) ${ }^{19}$
\end{abstract}

\footnotetext{
18 Apesar dos Guelfos não formarem um partido político unificado e seja difícil atribuir uma identificação única a eles, o traço geral que os une é o fato de serem pars Ecclesiae, ou "partido da Igreja". Sobre a origem do termo, ver: GILLI, Patrick. Cidades e sociedades urbanas na Itália medieval: (séculos XII-XIV). Campinas: Editora da Unicamp; Belo Horizonte: Editora da UFMG, 2011, p.36-37.

19 No original: II quadro politico dell'Italia delle città centro-settentrionali appare cioè più ricco e variegatodi quanto non si continui a ritenere secondo una visione prevalentemente "comu-". Regimi
} 


\section{O poder na Idade Média}

Lorene Correia Santos

A conjuntura de transformações políticas compreendeu desde a obtenção da autonomia jurídica frente a outros poderes territoriais, como o Papa ou o Imperador, a amplas mudanças institucionais nas formas de governo, que se estenderam até o século XIV.

O regime comunal pressupunha a participação política dos cidadãos, mas essa nunca foi sinônimo de presença política popular (JONES, 1965, p.76) ${ }^{20}$.

Apesar de todos os contrapesos e jugos constitucionais, o poder nas comunas italianas ligava-se obstinadamente à riqueza e migrava com os deslocamentos dela, e através de todas as revoluções dos regimes políticos e econômicos, a oligarquia, na prática ou nas leis, era a forma predominante de governo. No primeiro século das comunas, isso representou, na linguagem contemporânea, o governo dos chamados milites ou pedites que constituía o populus, e pela classe dos maiores ou milites, um grupo composto pela pequena nobreza feudal e comerciantes, que em Florença, por exemplo, eram cerca de 100 famílias. (JONES, 1965, p. 75, tradução nossa) ${ }^{21}$

Em fins do século XIII, as lutas pela supremacia do poder nas cidades também eram uma constante entre suas facções internas, integradas principalmente pelas famílias aristocráticas locais. Seus conflitos são outros dos fatores associados às

diversi e ibridi si alternarono, a partire dalla crisi delregime podestarile in età federiciana, con esiti spessolabili e incertie talora più stabili e duraturi. Questa apparente instabilità istituzio-nale fu espressione di una intensa sperimentazione politica, che nonsi svolse solo nel segno della partecipazione allargatama anche inquello del governo personale e monocrático.

${ }^{20}$ Como demonstram Jones (1965, p. 76) e Gilli (2011, p. 83), em nenhum momento da história comunal Popolo teve a conotação de popular, ou de "denominação universal". Popolo foi um grupo social heterogêneo, geralmente composto por associações de ricos comerciantes, banqueiros e outros homens de ofício, the popolani grassi.

${ }^{21}$ No original: "Despite all constituonal checks and balances, power in the Italian communes clung obstinately to wealth and migrated with movements of wealth, and through all revolutions of political and economic régime, oligarchy in fact or law, was the predominant form of government. In the first century of the commune this represented, in contemporary language, government of those called minotrites or pedites, who constituted the populus, by the class of maiores or milites, a composite group of feudal gentry and merchants, who in Florence, for example, may have numbered some 100 families". 


\section{O poder na Idade Média}

\section{O Governo das signorie na Crônica de Salimbene de Parma}

mutações políticas.

(...) as últimas décadas do século XIII e as primeiras do século XIV foram marcadas pela explosão de tensões sociais e políticas e pela incapacidade por parte dos governantes de colocar um fim a essa situação. As experimentações institucionais se mostraram geralmente ineficazes (colocados à parte os casos de Veneza e Siena) em razão da exasperação das rivalidades interurbanas e do peso da fiscalidade durante o regime dos populares, que procuraram fazer os nobres participar financeiramente de suas políticas; estes se recusam a isso tanto quanto podem e intensificam a exploração do contado, tudo em um contexto econômico que não cessa de se degradar globalmente a partir do fim do século XIII, atiçando a competição social. (GILLI, 2011, p. 91)

Também é observável uma progressiva insustentabilidade e enfraquecimento das instituições políticas citadinas, principalmente nos regimes 'podestadais'. Essa decadência institucional foi acompanhada de um processo de consolidação regional, no qual as cidades maiores 'engoliram' as menores, independentemente de suas formas e princípios governamentais (JONES, 1965, p.71). Ainda que algumas delas seguissem existindo, perderam protagonismo para o poder concentrado nos signori e nas autoridades oficiais apontadas por eles.

Como mencionado, a historiografia desse período tradicionalmente interpretou suas contínuas mudanças políticas como uma sucessão de crises ${ }^{22}$, onde as comunas representariam a expressão da liberdade dos citadinos, e a signoria, o resultado da degeneração moral e responsável pelo fim da liberdade política (ZORZI,2013, s/p), num contraponto entre liberdade e submissão.

O poder signorile mudou as cidades, principalmente quanto à sua centralização,

\footnotetext{
${ }^{22}$ A esse respeito, Andrea Zorzi constrói uma síntese tanto das linhas interpretativas tradicionais, que leram o período sob a ótica de uma sucessão de lutas internas e degeneração moral, responsáveis pela crise comunal, como também aponta os aspectos da renovação dos estudos historiográficos sobre o tema. Ver: ZORZI, Andrea. Toscana, terra anche di signori. In: (org). Le signorie cittadine in Toscana
} Esperienze di potere e forme di governo personale (secoli XIII-XV). Roma: Viella, 2013. s/p. 


\section{O poder na Idade Média}

Lorene Correia Santos

consolidação burocrática e endurecimento progressivo da dinâmica governamental. O desenvolvimento das signorie coincidiu com o esfacelamento do Império na Itália e as circunstâncias da morte de Frederico II (1250), bem como a derrota dos Staufen, também impactaram a realidade comunal (GILLI, 2011, p. 82). Nesse cenário conflituoso e incerto, apoiando-se na premência de paz e concórdia, os signori alicerçaram sua legitimidade sobre a justificativa de um governo unificado que garantisse a conciliação entre as diferentes facções citadinas ${ }^{23}$, assegurando a preservação coletiva dos valores cívicos relacionados ao bem comum. A paz e a concórdia cívicas nas cidades, por exemplo, eram questões que já suscitavam preocupação na Itália centro-setentrional desde a segunda metade do século XIII, e a busca pelo bem comum se tornou o principal eixo da dinâmica social e do bom governo.

As primeiras formas de poder dos signori começaram a se afirmar em meados do século XIII. Ainda que se dessem de maneiras diferentes em cada cidade, geralmente iniciavam-se através da atribuição de plenos poderes a um indivíduo. Essa incumbência poderia ser conferida pelos Conselhos ou Assembleia citadina ou a quem ocupava o cargo de capitano del popolo ou de podestà. Além disso, muitas vezes a atribuição era vitalícia e abarcava prerrogativas de sucessão.

A alteração de governos, o poder arbitrário, pessoal e ocasionalmente vitalício desses signori carregava consigo o peso das contradições sociais e políticas: os Signori, não raro, provinham de famílias já inseridas no contexto político, social e econômico das cidades, da aristocracia feudal ou consular.

\footnotetext{
${ }^{23}$ David Pepe afirma que a crise militar das sociedades citadinas tem uma relação íntima entre 0 exercício das armas e o desenvolvimento do novo regime (PEPE, 2012/2013, p. 23).
} 


\section{O poder na Idade Média}

\section{O Governo das signorie na Crônica de Salimbene de Parma}

As contendas anteriores entre Império e comunas, além dos citados conflitos internos, refletiam-se nas cidades, acirrando as lutas tomadas pela aristocracia militar. Após Frederico II, o eixo do conflito abarcou também a luta entre cidades. É nesse ínterim que o poder dos signori se consolida e se ramifica também para os âmbitos social e militar como parte do esforço de defesa territorial. O argumento da recuperação da paz e concórdia cívicas era vital também para a continuidade das signorie. Ele garantia o combate à violência entre as facções internas e o caminho possível para assegurar a concórdia cívica (MINEO, 2013, p.66), principalmente quando a estabilidade política era a prerrogativa central dos governos comunais.

Muitos desses signori ampliaram seus poderes sobre o sistema judiciário, os processos de expansão territorial e militar, as finanças e a administração, tornando nominal a representatividade das instituições comunais. "A comuna seria o espaço que possuía as condições necessárias para uma tirania se desenvolver: autônoma e autogovernada, era na cidade que as disputas pelo poder aconteciam e era ali também que o bem comum poderia ser substituído pelo bem particular" (SCHIRM, 2018, p. 191). A influência dos signori alcançou o âmbito extra-citadino, eventualmente dominando várias cidades de uma mesma região e constituindo um poder que poderia ser exercido de modo informal, ou de maneira oficializada e institucionalizada (GILLI, 2011, p.93-94). Frente à concentração progressiva do poder, a tirania passou a ser um vocábulo frequente entre os cronistas do contexto para designar esse fenômeno político, ou mesmo os governantes que alcançavam ou se perpetuavam no poder através da subversão das instituições.

Para Gilli (2011, p.372-373), a tradução das obras de Aristóteles do grego e sua difusão pelas universidades no século XIII, influenciaram a teorização das formas de governo no contexto comunal. O uso das palavras "tirania" e "tirano" coincide com 


\section{O poder na Idade Média}

Lorene Correia Santos

esse fato, e a reelaboração da linguagem aristotélica, empreendida principalmente por Tomás de Aquino ${ }^{24}$ (1225-1274), é um dos fatores que contribuíram para a "normatização" da palavra tirano a partir dos anos setenta do século XIII (MINEO, 2013, p.62). A tirania é transformada em uma categoria geral, designando governos que não respeitam o bem comum (MINEO, 2013, p. 62). Quando o governante subverte seu posto e corrompe a busca do bem comum, atendendo somente seus interesses particulares, tem-se o mau governo, a tirania.

(...)Tomás de Aquino, na segunda metade dos anos 1200, tinha derivado a noção de tirania como um poder exercido não para o bem comum, mas para o interesse próprio do tirano; e desta noção, então estendida a todas as formas de governo, não só as monárquicas, traçou o corolário da legitimidade do direito de resistência, desde que não fosse em detrimento da maioria. (TREGGIARI, 2018, p. 218, tradução nossa) ${ }^{25}$

Assim, na historiografia tem-se empreendido um esforço para distinguir entre tirania e signoria, ainda que as generalizações predominem. $\mathrm{O}$ advento das signorie não significa propriamente uma negação das comunas e de sua liberdade, mas uma modificação na maneira de governá-las (ZORZI, 2013). O tirano ou o governante corrupto não deve ser interpretado como sinônimo de signori, ou mesmo como traço absoluto das signorie. Ainda que se tornasse progressivamente o governo de um só, esse governante não era sinônimo de tirano.

Entretanto, os reais efeitos no interior das cidades do contraste entre os diferentes regimes permanecem indeterminados: os signori nem sempre foram

\footnotetext{
${ }^{24}$ Mineo explica que Tomás de Aquino não se limita a comentar as formas de governo, mas sim, afirma que o tirano é um rei injusto; a monarquia a melhor forma de regime; a tirania é o pior dos regimes corruptos; e a democracia, ainda que a forma corrupta da politia, é menos danosa (MINEO, 2013, p.62). ${ }^{25}$ No original: “(...) Tommaso d'Aquino, nella seconda metà del Duecento, aveva derivato la nozione di tirannia come potere esercitato non per il bene comune, ma per l'interesse proprio del tiranno; e da questa nozione, ora estesa ad ogni forma di governo, non solo monarchica, aveva tratto il corollario della legittimità del diritto di resistenza, sempre che non andasse a danno della maggioranza".
} 


\section{O poder na Idade Média}

\section{O Governo das signorie na Crônica de Salimbene de Parma}

despóticos e o governo comunal nem sempre significou participação universal, “o fato de um ou outro governante ser acusado de exercer uma tirania não estaria atrelado ao fato de ser um signore, mas sim à maneira como governava a comuna ou à forma ilegítima que utilizava para atingir essa condição" (SCHIRM, 2018, p. 246). Assim, não se aplica a elementar contraposição entre "ditadura" e "democracia", nem a identificação entre signore e tirano.

(...) nas comunas citadinas continuaram a funcionar, ainda sob os regimes 'tirânicos', organismos colegiados (as articulações de "deputati ad utilia civitatis" que em diversas cidades estabeleceram e precisaram as suas funções e competências) que gerenciavam a administração urbana ordinária, assegurando a continuidade; não são irrelevantes a atenção e o respeito (certamente inspirados por razões oportunas) que os signori citadinos manifestaram para com os estatutos citadinos, promovendo revisões e novas redações (VARANINI, 2012, p. 156, tradução nossa) ${ }^{26}$.

Os termos - signoria e tirania - não são intercambiáveis e não significam uma só forma de governo, mas duas, sendo a primeira um aspecto da administração comunal italiana na última metade do século XIV, e a tirania uma degeneração do poder - do bem comum em bem particular - sendo passível de ocorrer ou não em uma signoria. Essa não significava gestão absoluta e os signori poderiam enfrentar a oposição dos citadinos e a necessidade de negociar com as facções internas.

Em suma, o governo signorile foi resultado de uma das transições políticoinstitucionais que caracterizaram o período comunal, mais um dos regimes que nasceu nas cidades e alterou o seu arranjo político. As mudanças que realizou nas instituições citadinas foram diferentes das engendradas pelas formas de governo

\footnotetext{
${ }^{26}$ (...) nei comuni cittadini continuano a funzionare, anche sotto i regimi 'tirannici', organismi collegiali (ad. es le giunte di "deputati ad utilia civitatis" che in tante città si assestano e precisano le loro funzioni e competenze) che gesticono l'ordinaria amministrazione urbana, assicurando continuità; né è irrelevante l'atenzione e il rispetto (certo ispirati da ragioni di opportunità) che i signori cittadini manifestano per gli statuti cittadini, promuovendone revisioni e nuove redazioni.
} 


\section{O poder na Idade Média}

Lorene Correia Santos

precedentes, como uma maior centralização do poder, mas não significou a completa alienação política. Pensar a experiência das signorie como unificada e idêntica em todas as cidades é encarar todo um fenômeno governamental de forma simplista.

Como exposto, cada vez mais tem-se buscado interpretar a fase das signorie como uma das experimentações políticas comunais, dotada de nuances tanto no âmbito do poder institucional como nas práticas informais de ação política. O poder dos signori respondeu às lutas entre as facções internas e à necessidade de defesa territorial e ordenação comunal. É possível interpretar seu surgimento como parte do desenvolvimento das instituições citadinas, e não só como o resultado da corrupção ou outro aspecto da crise, que resultaria na deterioração e alienação do governo das cidades. É outra das fases dos governos citadinos e não a simples corrupção que explicaria seu fim.

\section{O governo na Crônica de Salimbene}

Salimbene dedica grande parte de sua Crônica aos relatos sobre diferentes governantes. Entre exemplos bons e ruins, conta de signori, podestàs - leigos e religiosos, Guelfos e Gibelinos -, ministros da Ordem dos Frades Menores e mesmo do próprio Frederico II. Por vezes, lança um olhar acentuado a certos personagens e os classifica como bons ou maus governantes, baseando-se em suas condutas de poder e fundamentando-se no que observava. O imperador Frederico II é um exemplo, o minorita o considera o próprio anticristo ${ }^{27}$.

Na Crônica temos visões de eventos ocorridos de 1168 a 1288 e o desencadeamento de disputas políticas ocupa seu horizonte narrativo. Em geral,

\footnotetext{
27 De acordo com (FOOTE, 2011, p.231), para Salimbene, a singularitas de Frederico II atingiu proporções demoníacas e personificava os apetites violentos incontidos da elite governamental italiana.
} 


\section{O poder na Idade Média}

\section{O Governo das signorie na Crônica de Salimbene de Parma}

Salimbene narra os episódios escolhidos com detalhes, destacando os que presenciou. A partir de 1236, como testemunha dos esforços de conquista de Frederico II na Lombardia, das lutas entre comunas e também de suas facções internas, o minorita encara a paz como o produto de breves momentos de bonança.

Salimbene lamenta as lutas e destruições que parecem comprometer o equilíbrio político comunal. Além disso, o impacto que esses contínuos conflitos têm nos vínculos morais dos citadinos também o aflige. "Ninguém poderia crer, se não houvesse visto como eu vi, os horrores que aconteceram naquela época, tanto aos homens quanto aos animais de todo o tipo. (...) Esta maldição das guerras invadiu toda a Romanha, se espalhando por toda parte e estragando-a, no tempo que estive lá" (PARMA, 2006, p. 75, tradução nossa) ${ }^{28}$. Ele vê a presença destrutiva de delitos e rapina nas cidades, consequências da ilegitimidade resultante da guerra contínua, outra das forças responsáveis pela ruína dos cidadãos.

Para analisar o que Salimbene nos conta, sua origem familiar, sua formação teológica e ethos espiritual franciscano devem ser considerados: a apreciação da ordem social, dos vínculos familiares e a preservação da hierarquia são valores vitais pois refletem a ordenação divina do mundo. É Capo (1977, p. 634) que ressalta que a aparente estima pelo poder e nobreza por parte de Salimbene, assim como a apreciação da hierarquia dentro e fora da Ordem, se relacionam com o seu nascimento em uma classe abastada. Assim, o seu apreço à ordem estabelecida, ao invés de traduzir apenas tendências aristocráticas, pode nos dizer mais da conjuntura social e religiosa de onde ele provém. Se considerarmos que para São Francisco de

\footnotetext{
${ }^{28}$ No original: Nessuno potrebbe credere, se non avesse veduto come ho visto io, gli orori che si compivano in quel tempo, tanto dagli uomini che dalle bestie di ogni specie. (...) E'sta maledizione dele guerre invase l'intera Romagna, dilagando da ogni parte e guastandola, nel tempo che io ero là.
} 


\title{
O poder na Idade Média
}

Lorene Correia Santos

Assis (1181/1182-1226), a ordem social e das coisas terrenas descendem e obedecem à ordem das coisas divinas, esses eram valores a serem respeitados em sua dinâmica, pois essa refletiam a vontade divina.

\begin{abstract}
Sem negar os traços distintivos dos dois franciscanos, é correto dizer que Salimbene e São Francisco compartilham um conservadorismo frente à ordem social e religiosa que os marca como perfeitos legatários da Cristandade medieval. Seus conservadorismos não eram tão dissimilares da ordem clássica do Hinduísmo, tomando o status social como certo e como o caminho que é dado para que se alcance a salvação. Enfraquecer a ordem hierárquica é prejudicar a salvação de si mesmo e dos outros. (FOOTE, 2011, p. 218, tradução nossa) ${ }^{29}$
\end{abstract}

Segundo Ronzani, (2018, p.256), ao falar de um bom governo, Salimbene valoriza certos preceitos do sistema comunal, como o respeito às leis e às instituições. Igualmente, ele estima a alternância entre os governos, que assim refletiam a obediência à ordem, à hierarquia e a administração da justiça estabelecidas. Em contrapartida, no uso do termo dominium, Salimbene se refere a um poder pleno e tendencialmente imensurável; no contexto comunal, isso significa quase sempre um poder mais amplo e menos regulado do que o exercido pelos magistrados comuns (RONZANI, 2018, p. 256-257).

$\mathrm{O}$ verdadeiro dominium foi como aquele exercido pelos homens mais próximos a Frederico: seu filho Enzo, Alberico e Ezzelino da Romano e Uberto Pallavicino, que haviam continuado a"signoriar" sobre mais cidades, impelido por seu insaciável "appetitum dominandi", bem depois de 1250. (RONZANI, 2018, p. 254-255, tradução nossa) ${ }^{30}$

\footnotetext{
${ }^{29}$ No original: Without denying the distinctive features of the two Franciscans, it is fair to say that Salimbene and St. Francis share a conservatism toward the social and religious order that marks themas thorough going children of medieval Christianity. Their conservatism was not too dissimilar from that of classical Hinduism, taking social status for granted as the path one is given for working out salvation. To undermine the hierarchical order is to undermine the salvation of oneself and others.

30 No original: Ovviamente, un dominium vero e proprio fu quello esercitato dagli uomini piu vicini a Federico, come suo figlio Enzo, oppure Alberico e Ezzelino da Romano, o l'Uberto Pallavicino che avrebbe continuato a "signoreggiare" su piu citta, spinto dal suo insaziabile "appetitum dominandi", ben dopo il 1250.
} 


\title{
O poder na Idade Média
}

\section{O Governo das signorie na Crônica de Salimbene de Parma}

Um exemplo disso é Ghilberto da Gente, que foi signore em Parma entre os anos 1253-1259 e apesar de dotado de plenos poderes e responsável pela momentânea pacificação da cidade, eventualmente a insatisfação popular o retirou do governo. Salimbene enumera algumas de suas ações que, para ele, foram as responsáveis pela perda de sua signoria. Essas vão desde características pessoais como avareza, passando pela deslealdade à Igreja, pela familiaridade com Uberto Pelavicino, até a revolta dos parmesãos. Isso demonstra, além do que Salimbene valoriza, que os signori, ainda que representassem um governo mais personalizado e centralizado, e alguns de fato se tornassem déspotas, não possuíam poder absoluto. Os cidadãos prezavam pela paz, mas isso não significava a aquiescência irrestrita às mudanças e imposições.

\begin{abstract}
E no tempo de sua signoria, reconduziu os cidadãos de Parma de volta à paz e mandou construir algumas portas de alvenaria na cidade: e isso foi bom. Mas ele também fez muito mal, como julgaram os parmesãos: e assim eles se levantaram contra ele, tomaram a signoria de suas mãos, destruíram suas casas em Campegine e Parma; e o enviaram a Ancona. (PARMA, 2006, p. 244, tradução nossa) $)^{31}$
\end{abstract}

Na Crônica os governantes que exerciam o regimen respeitavam os estatutos, as instituições comunais e a administração da justiça, contrastando com os exemplos de dominium. Tanto essa diferenciação é observável que os signori que exerciam o dominium, como o próprio Ghilberto, se dotavam de um poder exacerbado ou acrescido em seu exercício, são os mais próximos de Frederico II (RONZANI, 2018, p.255), como Ezzelino da Romano, seu irmão Alberico e Umberto Pelavicino.

\footnotetext{
31 No original: E nel tempo di sua signoria ricondusse i cittadini di Parma alla pace e fece costruire alcune porte della città in muratura: e questo fu bene. Ma operava anche molto del male, come fu deviso ai permegiani: e così alla fine insorsero a gran furore contro di lui e gli tolsero di mano la signoria e guastarono le sue case a Campegine e a Parma: e lo mandarono in bando ad Ancona.
} 


\section{O poder na Idade Média}

Lorene Correia Santos

Salimbene os destaca ao apontar as signorie que estavam sob um mau governo, além de que, os três são exemplos sintomáticos do contexto militarmente instável.

Em Treviso signoreggiava Alberico da Romano por muitos anos: feroz e cruel foi a sua signoria (...) Fingia estar em guerra com Ezzelino da Romano, seu irmão, para mais facilmente operar suas maldades. (...) Frequentemente impunha pesados tributos e multas à cidade (...) e ele não tinha nenhuma restrição em matar seus cidadãos e súditos" (PARMA, 2006, p. 176-177, tradução nossa) ${ }^{32}$.

Salimbene cita Ezzelino III diversas vezes, ressentindo sua ganância ou mesmo contrastando sua maldade com a bondade de São Francisco. Para ele, signori injustos e cruéis como ele permaneceram no domínio das cidades graças ao seu apetite de poder.

No resto da Marca signoreggiava o irmão desse Alberico, messer Ezzelino: isto é. a Pádua, a Vicenza e a Verona. Era um membro do diabo e filho da iniquidade. (...) Todos o temiam (...). Quem vivia hoje não tinha certeza do amanhã. O pai pedia a morte do filho: e o filho a do pai ou de outro parente, para agradar Ezzelino. (PARMA, 2006, p. 181, tradução nossa) ${ }^{33}$

Apesar do cenário desolador, Salimbene nomeia bons governantes, como Lambertesco dei Lamberteschi (1242) e Alberto Della Scalla (1277). Lambertesco, além do respeito às instituições citadinas, é valorizado na sua capacidade de ser justo com os cidadãos. Salimbene conta que o conselho municipal de Régio conferiu a Lambertesco plenos poderes e ele - que para Salimbene, era dotado de sabedoria e amor pelos citadinos - optou por usá-los para resolver problemas da própria comuna.

\footnotetext{
32 No original: A Treviso signoreggiava Alberico da Romano per molti anni: e feroce e spietata fu la sua signoria (...) E fingeva di aver guerra con Ezzelino da Romano, suo fratello, per potere più sfacciatamente operar ele sue malvagità (...) E imponeva così gravosi tributi e multe alla città e così di frequente, (...)E non avea ritegno in ammazzare i citadii e suddti suoi.

${ }_{33}$ No original: Nel resto della Marca signoreggiava il fratello de 'sto Alberico, messer Ezzelino: e cioè a Padova, a Vicenza e a Verona. Era sì um membro del diavol e figlio dell'iniquità. (...) Di lui tutti tremavano (...) Chi viveva oggi non era sicuro del domani. Il padre domandava la morte del figliolo: e il figliolo quella del padre o di qualche altro parente, per far piacere a Ezzelino.
} 


\section{O poder na Idade Média}

\section{O Governo das signorie na Crônica de Salimbene de Parma}

No ano de 1242 foi podestá de Régio Lambertesco dei Lamberteschi, florentino, que tinha amor a fazer o certo e o justo aos citadinos; [...] E então o Conselho municipal de Reggio, em uma quase unanimidade de votos the concedeu faculdade de fazer aquilo que desejasse. E, no mesmo ano, mandou construir a estrada de Reggiolo, as pontes sobre o cabo Tagliata, os poços no entorno do castelo de Reggiolo e mandou construir trinta jardas da torre. (PARMA, 2006, p. 65 ,tradução nossa) $)^{34}$

Após o assassinato de seu irmão Mastino, Alberto della Scalla ${ }^{35}$ vingou sua morte e o sucedeu no governo de Verona. Sua signoria é apreciada por Salimbene principalmente porque é um governante imparcial e justo.

(...) Alberto della Scalla, que se vingou asperamente matando os malfeitores. Ele ainda vive, tem a signoria e é muito amado pelos Veroneses, porque se comporta bem. É uma pessoa imparcial, tem discernimento, justiça e ama os pobres, como fazia seu irmão.( PARMA, 2006, p. 194-195, tradução nossa) ${ }^{36}$.

Todavia, ainda que encontre governantes zelosos com as instituições e cidadãos, o tom de Salimbene ao fim da Crônica é pessimista frente ao futuro político nas cidades italianas.

Na paz dos lombardos tenho pouca fé. A paz deles é como aquela brincadeira de crianças, na qual um coloca as mãos sobre os joelhos e o outro também as coloca sobre os seus. E quem quer que seja o vencedor, tira rapidamente uma mão e golpeia com força a do adversário: e assim grita vitória. (PARMA, 2006, p.308, tradução nossa) ${ }^{37}$.

\footnotetext{
${ }^{34}$ No original: L'anno 1242 fu podestà di Reggio Lambertesco dei Lamberteschi Fiorentino, che aveva amore a far ragione e giustizia ai cittadini; [...] E allora il Consiglio municipale di Reggio a quasi unanimità di voti gli concesse facoltà di fare quel che volesse. E nello stesso anno fece fare la strada di Reggiolo, i ponti sul cavo Tagliata, le fossa attorno al castello di Reggiolo e trenta braccia della torre.

35 Os Della Scala são exemplos que conseguiram, através do título de capitano del popolo, instaurar uma dinastia (GILLI, 2011, p.94)

${ }^{36}$ No original (...) Alberto della Scalla, che si vendicò asperamente uccidendo quei malfattori. Egli vive tuttora e si tiene la signoria ed è amato assai dai Veronesi, perché si comporta bene. È una persona imparziale, tien ragione e giustizia e ama i poveri, come faceva il fratello suo.

37 No original: Nella pace dei Lombardi ho bem poca fiducia. La loro pace è come quel gioco dei ragazzi in cui uno posa le mani sulle so' ginocchia e l'altro vi mette sopra le sue. E chi vuol esser il vincitore, tira via prontamente dal si sotto una mano e percuote forte su quella dell'avversario: e grida così vittoria.
} 


\section{O poder na Idade Média}

Lorene Correia Santos

Ele vê a paz no interior das comunas como momentânea, parece descrente quanto à moral compartilhada pelos cidadãos e ao mesmo tempo enxerga a solidez da concórdia cívica como um desejo distante.

\section{Conclusão}

O artigo intentou analisar as caracterizações de governo dos signori presentes na Crônica de Salimbene de Parma. Primeiro, tecemos uma perspectiva das crônicas citadinas e das crônicas mendicantes, identificando suas motivações e usos para que melhor situássemos a Crônica em seu meio. Também pontuamos alguns dos conflitos presentes no texto que tornam impossível enquadrar a obra em apenas um gênero.

Em seguida, descrevemos um panorama do advento das signorie, essas formas de governo mais personalizadas e centralizadas do que as precedentes, da Itália do século XIII. Isso se fez necessário no esforço de contextualização desse trabalho, principalmente por esse ser o período menos estudado da Idade Comunal, e tradicionalmente lido como o resultado da destruição dos regimes precedentes.

Por fim buscamos, a partir de seu contexto cultural e reflexões políticas, analisar os governos que Salimbene descreve. Procuramos considerar o quanto a escrita da história para o frade - balanceando objetivos sociais, espirituais e funcionalidade na Crônica -, está ligada ao seu potencial edificador, tal qual a literatura mendicante do período. Assim como diferentes formas de governo, boas e ruins, justas e injustas, diferentes frações da vida de Salimbene se entrelaçam em sua obra. Portanto, suas convicções políticas, heranças contextuais, procedência familiar abastada, alinhamento político Guelfo e, principalmente, sua formação intelectual e religiosa como frade minorita, balizaram nossa análise de suas caracterizações e 


\section{O poder na Idade Média}

O Governo das signorie na Crônica de Salimbene de Parma

juízos: o que valoriza e aprova, como a observância das leis, a justiça e o zelo pelos citadinos, e o que rechaça e condena nos fatos sociais e políticos relatados, como o abuso do poder, a ganância, e a crueldade para com os governados.

Salimbene viu a paisagem política da Itália se transformar, e é também desejando compreender estas transformações que ele escreve, uma narrativa que exemplifica e representa seu tempo de mudanças, contendas e continuidades. De todas as formas, as potencialidades de estudo acerca das signorie na Crônica não se esgotaram. Salimbene ainda tem muito a oferecer ao historiador dos dias atuais.

Fonte

ADAM, Salimbene de. Cronaca. 2 ed. Reggio Emilia: Diabasis, 2006. 397p.

Referências bibliográficas

ARTIFONI, Enrico. I governi di "popolo" e le istituzioni comunali nella seconda metà del secolo XIII. Reti Medievali Rivista, v. 4, n. 2, p. 1-20, 2003.

ASCHERI, Mario. Il comune medievale italiano: un tema da discutere. LE CARTE E LA STORIA, n. 1, p. 14-25, 2017.

- Riconsiderare la civiltà comunale: con Maire Vigueur e oltre. Bollettino Roncioniano. Prato, VI, p. 9-20, 2006.

BALBI, Giovanna Petti. Lignaggio, famiglia, parentela in Salimbene. Atti del convegno per il VII centenario di Fra Salimbene. Bologna, 1991. p. 35-47.

BARONE, Giulia. L'ordine dei predicatori e le città. Teologia e politica nel pensiero e nell'azione dei predicatori. Mélanges de l'Ecole française de Rome. Moyen-Age, Temps modernes v. 89, n. 2, p.609-618, 1977.

Federico II di Svezia e gli Ordini Mendicanti. Mélanges de l'Ecole française de

Rome. Moyen-Age, Temps modernes, v. 90, n. 2, p. 607-626, 1978. 


\section{O poder na Idade Média}

\section{Lorene Correia Santos}

BARTOLA, Alberto. Salimbene e i suoi autori. Compresenze e intertestualità nella Cronica. In: LIV. Salimbene de Adam e "La Cronica", 2017, Todi. Atti del centro italiano di studi sul basso medievo. Spoleto: Fondazione Centro Italiano di Studi Sull'Alto Medioevo, 2018. p.85-106.

BLANSHEI, R. Sarah. Politics and justice in late medieval Bologna. Leiden; Boston: Brill, 2010.

BORDINI, Simone. Una selva di citazioni: La "Cronica" di Salimbene tra storia e autobiografia intellettuale. Parole Rubate, n. 3, p. 3- 26, 2011.

CACIORGNA, Maria Teresa. Beni comuni e storia comunale. In: $\therefore$ CAROCCI Sandro; ZORZI Andrea (org.). I comuni di Jean-Claude Maire Vigueur. Percorsi storiografici. 1. ed. Roma: Viella, 2014. p. 33-50.

CAPO, Lidia. Cronache mendicanti e cronache cittadine. In: Mélanges de I'Ecole française de Rome. Moyen-Age, Temps modernes. v. 89, n. 2. p. 633-639, 1977.

CAROCCI, Sandro. Storia di Roma, storia dei comuni. In: CACIORGNA Maria Teresa; $\therefore$ ZORZI Andrea (org.). I comuni di Jean-Claude Maire Vigueur. Percorsi storiografici. 1. ed. Roma: Viella, 2014. p. 51-68.

CREMASCOLI, Giuseppe. Le fonti bibliche. In: LIV. Salimbene de Adam e "La Cronica", 2017, Todi. Atti del centro italiano di studi sul basso medievo. Spoleto: Fondazione Centro Italiano di Studi Sull'Alto Medioevo, 2018. p. 69-84.

COLEMAN, Edward. The Italian communes. Recent work and current trends. Journal of Medieval History, Grã-Bretanha, v.25, n.4, p. 373-397, 1999.

CORTESE, Elena Maria. Aristocrazia signorile e città nell'Italia centro-settentrionale (séc. XI-XII). In: CACIORGNA Maria Teresa; CAROCCI Sandro; ZORZI Andrea (org.). I comuni di Jean-Claude Maire Vigueur. Percorsi storiografici. 1. ed. Roma: Viella, 2014. p. 69-94.

DOLSO, Maria Teresa. Frati Mendicanti e città nella Cronica. In: LIV. Salimbene de Adam e "La Cronica", 2017, Todi. Atti del centro italiano di studi sul basso medievo. Spoleto: Fondazione Centro Italiano di Studi Sull'Alto Medioevo, 2018. p.267-304.

FOOTE, David. Mendicants and the Italian Communes in Salimbene's Cronaca. In: PRUDLO, Donald S. (org.). The Origin, Development and Refinement of Medieval 


\section{O poder na Idade Média}

O Governo das signorie na Crônica de Salimbene de Parma

Religious Mendicancies. 1. ed. Boston: Brill, 2011. p. 198-238.

GILLI, Patrick. Cidades e sociedades urbanas na Itália Medieval. Séculos XII-XIV. Campinas: Unicamp; Belo Horizonte: UFMG, 2011. 414 p.

JONES, Philip J. Communes and Despots: The City State in Late-Medieval Italy. In: Transactions of the Royal Historical Society. V.15, p. 71-96, 1965.

LAVAGETTO, Mario. Introduzione: II papa e II negromante. IN: ADAM, Salimbene de. Cronaca. 2 ed. Reggio Emilia: Diabasis, 2006. p.VII - XL.

MIATELLO, André Luiz Pereira. Salimbene de Parma e a escrita da história no século XIII. In: Anais do XXVI Simpósio Nacional de História, XXVI., 2011, São Paulo. Anais Eletrônicos. São Paulo: ANPUH, 2011. p. 1-13. Disponível em: http://www.snh2011.anpuh.org/resources/anais/14/1300665568 ARQUIVO Salimben edeParmaeaescritadahistorianoseculoXIII.pdf. Acesso em 21 jul. 2020.

- Relações de poder e bem comum na Baixa Idade Média Italiana (séc. XIII-XIV). Anos 90, Porto Alegre, v. 20, n. 38, p. 181-217, dez 2013.

MILANI, Giuliano. Partecipare al comune: inclusione, esclusione, democrazia. In: II Governo delle città nell'Italia comunale. Una prima forma di democrazia?. 2005, Prato. Atti della giornata di studi. Prato, 2007. p. 35-49.

. L'esclusione dal comune: Conflitti e bandi politici a Bologna e in altre città italiane tra XII e XIV secolo. Roma: Istituto storico italiano per il Medio Evo, 2003.

MILNE, Ana. Sacerdos et Predicator: Franciscan 'Experience' and the Cronica of Salimbene de Adam. 2010. 159 f. Dissertação (Mestrado em História) - Departamento de História, University of Canterbury, Christchurch, 2010.

MINEO, E. Igor. "Necessità della tirannide": governo autoritario e ideologia della comunità nella prima metà del Trecento. In: ZORZI, Andrea (ed.). Tiranni e tirannide nel Trecento italiano. Roma: Viella, 2013. p. 59-75.

PEPE, Davide. Varietà di dinamiche dell'affermazione signorile nella Cronaca di Salimbene de Adam: Breve Antologia. 2012/2013. 72 f. Monografia (Graduação trienal em Letras) - Università degli studi di Roma Tor Vergata, Roma, 2013.

PIO, Berardo. Il bene comune: forme di governo e gerarchie sociali nel basso medioevo. In: Atti del XLVIII Convegno storico internazionale, Spoleto: Fondazione 


\section{O poder na Idade Média}

\section{Lorene Correia Santos}

Centro Italiano di Studi Sull'Alto Medioevo. 2012. p. 35-61.

RONZANI, Mauro. Salimbene tra poteri universali e realtà comunali. In: LIV. Salimbene de Adam e "La Cronica", 2017, Todi. Atti del centro italiano di studi sul basso medievo. Spoleto: Fondazione Centro Italiano di Studi Sull'Alto Medioevo, 2018. p. 251-265.

SCHIRM, Letícia Dias. Le città d'Italia tutte piene son di tiranni: tirania, bem comum, cidade e governo na península itálica da segunda metade do século XIV e início do século XV. 2018. 301 p. Tese (Doutorado em História) - Faculdade de Filosofia e Ciências Humanas, Universidade Federal de Minas Gerais, Belo Horizonte, 2018.

TREGGIARI, Ferdinando. La parabola del bene comune: ordine pubblico e milizie cittadine. Atti del XLVIII Convegno storico internazionale, Spoleto: Fondazione Centro Italiano di Studi Sull'Alto Medioevo, 2012. p. 265-302.

Democrazia e tirannide: il laboratorio medievale (a proposito della traduzione dei trattati politici di Bartolo da Sassoferrato. Rivista di Storia del diritto italiano, Anno XCl. v. XCl, p. 215-223, 2018.

VALLERANI, Massimo. Comune e comuni: una dialettica non risolta. In: Sperimentazioni di governo nell'Italia centro-settentrionale nel processo storico dal primo comune alla signoria, 2010, Bolonha. Atti del convegno di studio. Bolonha: Bononia University Press, 2011. p. 9-34.

VARANINI, Gian Maria. I notai e la signoria cittadina. Appunti sulla documentazione dei Bonacolsi di Mantova fra Século XIIII e Trecento (rileggendo Pietro Torelli). Reti Medievali Rivista, Firenze, v. 4, n. 2, p. 1-20, 2008.

. Le signorie trecentesche e Francesco Petrarca. Appunti Storiografici. In: Atti del Convegno Internazionale, 2004, Firenze. Quaderni Petracherschi XV-XVI. Firenze: Casa Editrice Le Lettere, 2005-2006. p. 151-168.

. Comuni cittadini italiani e istituzioni ecclesiastiche (inizi XIII sec.). Spunti dalla ricerca recente. In: CACIORGNA Maria Teresa, CAROCCI Sandro; ZORZI Andrea (org.). I comuni di Jean-Claude Maire Vigueur. Percorsi storiografici. 1 ed. Roma: Viella, 2014. p. 305-326.

VIGUEUR, Jean-Claude Maire. Le rivolte cittadini contro i "tiranni". In: BOURIN, M.; CHERUBINI, G.; PINTO, G. (org.). Rivolte urbane e rivolte contadine nell'Europa del Trecento: Florença: Firenze University Press, 2009. 


\section{O poder na Idade Média}

O Governo das signorie na Crônica de Salimbene de Parma

ZABBIA, Marino. La cronachistica cittadina al tempo di Salimbene de Adam. In: Salimbene de Adam e La "Cronica". Atti del LIV Convegno storico internazionale, Spoleto: Fondazione Centro Italiano di Studi Sull'Alto Medioevo, 2018. p. 219-233.

Tipologie del tiranno nella cronachistica bassomedievale. In: ZORZI, Andrea (org.). Tiranni e tirannide nel Trecento italiano. Roma: Viella, 2013. p. 171-203.

ZORZI, Andrea. La cultura della vendetta nel conflitto politico in età comunale. In: . \& DONNE, Roberto delle (org.). Le Storie e la memoria: in onore di Arnold Esch. Florença: Firenze University Press, 2002. p. 135-170.

. La trasformazione di un quadro politico: ricerche su politica e giustizia a Firenze dal comune allo Stato territoriale. Firenze: Firenze University Press, 2008.

I conflitti nell'Italia comunale. Riflessioni sullo stato degli studi e sulle prospettive di ricerca. In: . (org.). Conflitti, paci e vendette nell'Italia comunale. Florença: Firenze University Press, 2009, cap.1, p.7-42.

Premessa. In: Tiranni e tirannide nel Trecento italiano. Roma: Viella, 2013. Prefácio, p. 7-9.

. "Fracta est civitas magna in tres partes": Conflitto e costituzione nell'Italia comunale. Scienza \& Politica, n. 39, p. 61-87, 2008.

- Toscana, terra anche di signori. In: .(org). Le signorie cittadine in Toscana Esperienze di potere e forme di governo personale (secoli XIII-XV). Roma: Viella, 2013. Prefácio, s/p. 